\title{
Review
}

\section{Epidemiology of Cytomegalovirus among pregnant women in Africa}

\author{
Doreen Mhandire ${ }^{1,2}$, Sarah Rowland-Jones ${ }^{3}$, Kudakwashe Mhandire ${ }^{1,2}$, Mamadou Kaba², Collet \\ Dandara ${ }^{1,2}$
}

\author{
${ }^{1}$ Division of Human Genetics, Department of Pathology, Faculty of Health Sciences, University of Cape Town, \\ Cape Town, South Africa \\ ${ }^{2}$ Institute of Infectious Disease and Molecular Medicine, University of Cape Town, Cape Town, South Africa \\ ${ }^{3}$ Nuffield Department of Medicine, Oxford University, Oxford, United Kingdom
}

\begin{abstract}
Introduction: Vertical transmission of Cytomegalovirus (CMV), resulting in congenital CMV (cCMV) infection could have disabling and potentially fatal effects on the foetus or neonate. Although primary infection probably has a higher risk of leading to cCMV, in highly seropositive populations, a significant risk of vertical transmission is thought to be due to CMV reactivation and or reinfection during pregnancy. In this narrative review, we summarise the prevalence of CMV infection and associated risk factors among pregnant African women, in a setting where primary CMV infection usually occurs during infancy.

Methodology: A systematic search of literature published between January 2000 and January 2019, retrieved on five bibliographic databases was performed. Search for relevant articles was performed using the following keywords: cytomegalovirus, CMV, infection, antenatal infections, pregnancy, pregnant women, gravidity, developing countries and Africa, with appropriate qualifiers such as OR, AND.

Results: Systematic searching retrieved 11 relevant original research papers. Prevalence of anti-CMV IgG and IgM antibodies ranged from 60$100 \%$ and $0-15.5 \%$, respectively. Prevalence of CMV DNA ranged from 0-29\%, depending on the specimen used. However, there was no geographic trend for CMV seroprevalence or CMV DNA prevalence across the African continent. Overall, a substantial percentage of women of reproductive-age were CMV seronegative and at risk of primary infection. Associations of sociodemographic factors with CMV infection were inconsistent across all reviewed studies.

Conclusions: The limited data and inconsistency of findings from the few studies carried out in Africa calls for prospective studies comparing prevalence and outcomes of cCMV in infants born to women with both primary and reactivated CMV in Africa.
\end{abstract}

Key words: cytomegalovirus; prevalence; risk factors; pregnant; pregnancy.

J Infect Dev Ctries 2019; 13(10):865-876. doi:10.3855/jidc.11373

(Received 20 February 2019 - Accepted 26 June 2019)

Copyright (C) 2019 Mhandire et al. This is an open-access article distributed under the Creative Commons Attribution License, which permits unrestricted use, distribution, and reproduction in any medium, provided the original work is properly cited.

\section{Introduction}

Cytomegalovirus (CMV) is the second most common cause of congenital viral infections in the developing countries, after HIV [1]. Congenital CMV (cCMV) occurs when there is transmission of CMV from the mother to the infant in utero or perinatally. Congenital CMV is diagnosed by the detection of CMV DNA in any of the infant's body fluids within the first 21 days of life [2]. Because CMV infection or reactivation takes advantage of decreased or compromised immunity, pregnant women are particularly at risk of CMV reactivation due to the immune down-regulation which occurs in pregnancy. Pregnancy has been described as an immunological condition which presents multiple challenges in diagnosis, prevention and management of infectious diseases [3].
Maternal immunity acquired against CMV prior to conception does not confer complete protection to the developing foetus, as is the case with the other antenatal and perinatal congenital infections such as toxoplasmosis and rubella. As a result, vertical transmission of CMV can occur in both primary and non-primary maternal infections with rates of $30 \%$ and $2 \%$, respectively [4-5]. It was previously believed that vertical transmission of $\mathrm{CMV}$ and severe neonatal symptoms of cCMV only occur in infants born to mothers with primary infection in pregnancy. However, over $60 \%$ of the infants infected in utero with CMV are born to mothers with preconceptional immunity who have secondary infection in pregnancy, and more and more studies show severe sequelae in these infants. We therefore conclude that congenital CMV may be a significant problem even in children born to mothers with pre-pregnancy immunity [6-10]. Because cCMV 
prevalence $(\sim 3 \%)$ is higer in resource-limited settings where previous maternal infection is widespread, the majority of cCMV cases are a result of non-primary maternal infections compared with the developed world which has cCMV prevalence of $\sim 0.3 \%$ [11-12]. The role of non-primary CMV infection in cCMV has been shown in Brazil where a maternal CMV seropositivity of $\geq 97 \%$ resulted in more cases of cCMV compared to primary maternal infection [13-14]. Similar data are lacking in Africa despite a high seroprevalence of CMV and a likely growing burden of children with cCMV associated sequelae. This may justify the use of invasive methods for the detection of possible fetal infection even in cases of secondary CMV infection. This also brings in an additional problem, when considering the need for immunisation strategies against $\mathrm{CMV}$, as current vaccine development is primarily aimed at seronegative women to prevent primary infection. Furthermore, CMV infection during pregnancy increases the risk of spontaneous abortions [15].

Identification and treatment of cCMV is complicated as only $10-15 \%$ of infected infants present with symptoms at birth, and current guidelines recommend giving antiviral therapy only to symptomatic infants. However, as many as $15 \%-25 \%$ of asymptomatic infants go on to develop CMVassociated sequelae, particularly hearing loss $[9,16]$. Treatment of cCMV, especially in Africa, is further complicated by the high cost of antiviral drugs. The recommended $16 \mathrm{mg} / \mathrm{kg}$ twice daily dose of valganciclovir for six months costs approximately USD1820 [17-18]. This cost is out of reach for most people in developing countries who survive on less than USD1 per day and whose governments are already battling to sustain HIV antiretroviral therapy programs [19-20]. Moreover, in some cases, resistance against the widely used ganciclovir has been reported [21]. Further, the asymptomatic viral shedding of CMV sustains lack of recognition and underdiagnosis of the infection and risks of onward transmission.

Currently, there are no ideal safe and effective interventions to control CMV infection in pregnancy, as animal studies have shown teratogenicity associated with the principal anti-CMV agent, valganciclovir, when used in early pregnancy. There are currently no data on the teratogenicity of valganciclovir in humans [22]. In the absence of an effective vaccine, timely and robust diagnosis of maternal CMV infection and identification of mothers at highest risk of transmitting CMV becomes a priority so that infants with cCMV infection can be diagnosed and treated.
The prevalence of CMV differs among populations and regions, with Africa being one of the regions with the highest prevalence: Africa (>95\%), South America (> 95\%), Asia (81-95\%), North America $(\leq 70 \%)$, Australia $(\leq 65 \%)$, Europe $(\leq 60 \%)$ [23-24]. Surprisingly, despite the high prevalence reported in the few studies done in Africa, most African countries lack CMV prevalence reports, especially in pregnant women. In addition, while identification of factors influencing the vertical transmission of CMV is critical in curbing new infections, very little is documented on these factors. As the world focuses on the WHO-led 9090-90 targets for HIV diagnosis, treatment and control [25], important co-infections such as CMV are neglected. In view of the potentially disabling and/or fatal effects of congenital CMV infection, we summarise the prevalence and associated risk factors of CMV infection among pregnant women in Africa.

\section{Methodology}

We conducted a systematic literature search for this narrative review which summarises the seroprevalence/prevalence of CMV infection and associated risk factors among pregnant African women.

\section{Definition of CMV infection}

In this review, the following terms are used and should be defined to understand the different types of CMV infection status [26]. CMV seropositive refers to presence of either CMV IgM or IgG antibodies in either serum or plasma. CMV IgG seropositivity is used as a marker of exposure to CMV at some point during an individual's lifetime. CMV IgM seropositivity is a marker of CMV infection in a previously CMV seronegative individual (primary infection) or CMV reactivation/reinfection in a CMV IgG seropositive individual (secondary infection). CMV IgG antibody avidity is the aggregate strength with which CMV IgG antibodies bind to the CMV antigens. IgG antibody avidity gives a reflection of how long antibodies have been in circulation, following exposure to an antigen. The longer the antibodies would have been in circulation, the higher the avidity and vice versa [27]. Therefore, low avidity antibodies are a better marker of recent and/or active ( $\leq 6$ weeks) infection, following a positive CMV IgM test [28]. CMV DNAemia is defined as the presence of CMV DNA in blood, while CMV shedding is the presence of CMV DNA in any other body fluids. 


\section{Study selection}

Literature for this review was accessed from PubMed/ Medline, Scopus, EBSCOHost, African Journals Online (AJOL) and Institute for Scientific Information (ISI) web of knowledge databases. The search terms were as follows: (cytomegalovirus OR CMV OR CMV infection) AND (antenatal infections) AND (pregnancy OR pregnant women OR gravidity) AND (Africa OR developing countries). The search strategy was discussed by all authors, adjusted to ensure maximum relevance and read by DM. The identified papers were then read by DM and results were recorded in Table 1, in which we entered details about the study population, method of CMV diagnosis, country and province/city of study as well as CMV seroprevalence/prevalence. We then compared the details of included papers for commonalities.

\section{Results}

The search strategy, summarised in Figure 1 yielded 78 articles, whose abstracts were all reviewed. Sixtyfour abstracts were excluded for one or more of the following reasons: were not carried out in Africans/African countries; did not report on seroprevalence or prevalence of CMV. Three of the remaining 14 full text articles were excluded because the studies did not focus on pregnant women. Only full text articles published in English were included in this
Figure 1. Flow diagram of the article searches yielded, excluded and reviewed for the purpose of this review.

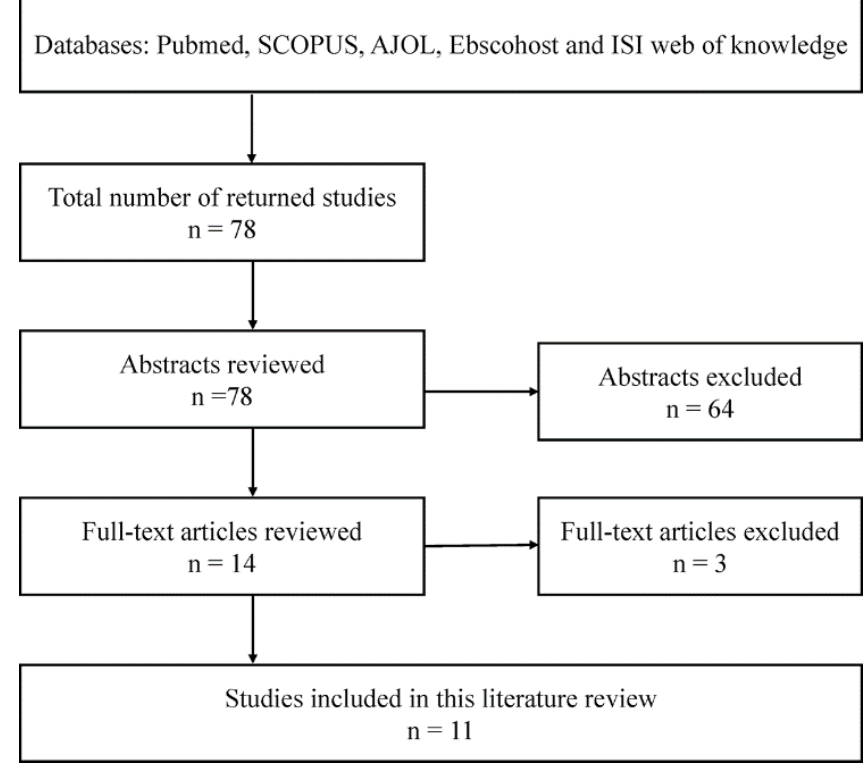

review. An article publication date range of January 2000 to January 2019 was selected to enable a sample of studies large enough to inform meaningful discussion and recent enough that it reflects current practice. We accessed 11 full articles reporting the prevalence of CMV in pregnancy in Africa. Of the 11 studies, two were conducted in North Africa (both in

Table 1. Summary of findings from the studies reviewed.

\begin{tabular}{|c|c|c|c|c|c|}
\hline \multirow{2}{*}{$\begin{array}{l}\text { Region and } \\
\text { country }\end{array}$} & \multirow{2}{*}{ *Study population } & \multicolumn{3}{|c|}{ CMV status } & \multirow{2}{*}{ Reference } \\
\hline & & DNA (n) & IgM \% & IgG \% & \\
\hline \multicolumn{6}{|l|}{ East Africa } \\
\hline Kenya & 260 women at Thika hospital & ND & 8 & 77 & {$[36]$} \\
\hline Ethiopia & 200 women in Addis Ababa & ND & 16 & 89 & {$[35]$} \\
\hline Sudan & 231 women in El-Rahad & ND & 3 & 72 & {$[37]$} \\
\hline Tanzania & 261 women in Mwanza & ND & 0.4 & 74 & {$[38]$} \\
\hline \multicolumn{6}{|l|}{ North Africa } \\
\hline Egypt & 546 women in Ismailia & ND & 7 & 100 & {$[30]$} \\
\hline Egypt & $\begin{array}{l}62 \text { women ( } 50 \text { with a history of recurrent } \\
\text { spontaneous abortion (cases), } 12 \text { with no history } \\
\text { of spontaneous abortion (controls) in Mansoura) }\end{array}$ & $\begin{array}{l}12 \text { in cases } \\
0 \text { in controls }\end{array}$ & ND & ND & [29] \\
\hline \multicolumn{6}{|l|}{ West Africa } \\
\hline Ghana & 72 women in Jomoro & ND & 0 & 100 & {$[32]$} \\
\hline Nigeria & 174 women in Osogbo & ND & & 60 & {$[33]$} \\
\hline Gambia & 169 HIV-infected women in Sukutu & $\begin{array}{c}\text { Vaginal swab }-24 \\
\text { Colostrum }-29 \\
\text { Saliva }-13 \\
\text { Urine }-1 \\
\text { Plasma }-2\end{array}$ & & 100 & {$[31]$} \\
\hline $\begin{array}{l}\text { Nigeria } \\
\text { Southern } \\
\text { Africa }\end{array}$ & 180 women in Kano & ND & ND & 91 & {$[34]$} \\
\hline Malawi & $81 \mathrm{HIV}$-infected ART-naïve women in Blantyre & ND & ND & 100 & [39] \\
\hline
\end{tabular}


Egypt [29,30]), four in West Africa (one in each of Gambia [31] and Ghana [32], two in Nigeria [33,34]), four in East Africa (one in each of the following countries; Ethiopia [35], Kenya [36], Sudan [37] and Tanzania [38]); and one in Southern Africa (Malawi) [39].

\section{Prevalence of Cytomegalovirus in pregnancy}

All studies reported CMV IgG seroprevalence, with five concurrently reporting CMV IgM results. Prevalence of anti-CMV IgG seropositivity during pregnancy in Africa ranged from $60 \%$ to $100 \%$. Four of the 11 studies (conducted in Gambia, Egypt, Malawi and Ghana) reported 100\% CMV IgG seroprevalence, demonstrating that the entirety of the study participants in these studies had been exposed to CMV in their lifetime. This is in keeping with studies in Gambian infants which showed that $100 \%$ of children acquired CMV infection by the age of eighteen months [10]. Two of the 11 studies reviewed reported on the prevalence of CMV DNA. Table 1 presents an overview of all the studies included in this review as well as CMV prevalence.

Factors associated with acquisition of CMV in African pregnant women

\section{HIV co-infection}

Two studies from Gambia and Malawi enrolled HIV-infected women only. The Kenyan study enrolled both HIV-infected and HIV- uninfected women in order to investigate HIV as a risk factor for CMV infection in Kenyan pregnant women. The Kenyan study reported no significant association between HIV status and CMV infection [36]. The remaining eight studies did not consider HIV as a risk factor for CMV infection or did not have data on the HIV status of participants despite the known biological interactions between HIV and CMV.

\section{$\underline{\text { Socio-economic status }}$}

None of the reviewed studies considered socioeconomic status as a correlate of CMV acquisition. However, several factors can be considered markers of socio-economic status, among them, place of residence, employment status, income and level of education [40]. The study carried out in Kenya reported on a significant association between risk of CMV infection and low levels of education (Odds ratio $(\mathrm{OR})=3.8,95 \% \mathrm{CI}=$ 3.023-6.96, p < 0.001) [36]. Hamid et al. [34] did not find any significant association between occupation and CMV seropositivity in Nigerian pregnant women. Contrary to findings from the Nigerian study, a study among Sudanese women [37], where an association between illiteracy and CMV IgG seropositivity ( $\mathrm{p}<$ 0.05 ) was reported. However, the study carried out among Sudanese women did not report odds ratios or $95 \%$ confidence intervals. A study done on a Tanzanian cohort reported urban residence to be a risk factor for CMV IgG seropositivity (OR $=6.329,95 \%$ CI $2.885-$ 13.887, $\mathrm{p}<0.001)$ [38].

\section{Maternal age and parity}

Three of the 11 studies in this review investigated age as a risk factor for CMV acquisition in pregnancy. Zaki and Goda [29] reported a significantly ( $<<0.001)$ higher median age among IgG seropositive (median = 25, IQR 19-27) compared to that of IgG seronegative (median $=20$, IQR 18-20) Egyptian women. Among Tanzanian women, a one-year age increase resulted in a $0.3 \%(95 \%$ CI $0.13-0.47, \mathrm{p}=0.001)$ increase in seroprevalence while at the same time the risk of being CMV IgG positive increased by $24 \%$ [38]. Hamdan et al. [37] observed that advanced maternal age was associated with a higher risk of CMV seropositivity in Sudanese pregnant women. However, the significance was lost after multivariate analysis [37], suggesting that the influence of maternal age on CMV acquisition could perhaps be marginal. Studies done in Kenyan and Nigerian women did not report any association between maternal age and risk of CMV seropositivity [34,36]. Higher parity was found to be significantly associated with a higher risk of CMV infection in the studies carried out in Tanzanian (OR $=2.9,95 \%$ CI 1.6-5.4, $\mathrm{p}$ $<0.001)$, Kenyan (OR $=3.8,95 \%$ CI 3-7, p $<0.0001)$ and Sudanese $(\mathrm{OR}=15,95 \%$ CI 2-123, $\mathrm{p}=0.01)$ pregnant women [34,36-38].

\section{Blood transfusion}

Two of the 11 studies investigated history of blood transfusion as a risk factor for CMV seropositivity $[33,36]$. There was a significant difference $(p<0.05)$ in CMV IgG seropositivity between women who previously had a blood transfusion $(93 \%)$ compared to women without a transfusion history (82\%) among Nigerian women [34]. This finding was confirmed by observations in the Kenyan cohort, where history of blood transfusion was associated with both CMV IgG and IgM antibody seropositivity [36].

\section{Recurrent spontaneous abortion}

Four of the 11 studies investigated CMV seropositivity as a risk factor for history of recurrent spontaneous abortion [29,35,37-38]. CMV seropositivity was reported to be significantly 
associated with history of spontaneous abortion in the Tanzanian study, both in univariate $(\mathrm{OR}=5.6,95 \% \mathrm{CI}$ $1.3-24.2, \mathrm{p}<0.02)$ and multivariate analysis $(\mathrm{OR}=5.2$, $95 \%$ CI $1.1-24.4, p=0.038$ ) [38]. In addition to a significant association between IgG seropositivity and history of spontaneous abortion in the Tanzanian cohort, the only woman who was CMV IgM seropositive had adverse birth outcomes with a low birth weight baby who also had microcephaly and spina bifida, consistent with a cCMV diagnosis [38]. In contrast, Yeshwondm et al. [35], Hamdan et al. [37] as well as Zaki and Goda (29) reported no significant association between history of spontaneous abortion and CMV infection in Ethiopian, Sudanese and Egyptian pregnant women, respectively.

\section{Discussion}

Seroprevalence of $C M V$

The prevalence of CMV observed in African countries is generally higher than the average $40 \%$ to $70 \%$ reported in the developed world [41]. The seroprevalence estimates reported in all the studies reviewed here were obtained using enzyme linked immunosorbent assays (ELISA) and therefore can be regarded as relatively comparable. Of all the methods used to detect presence of antibodies, ELISA has been found to be the most superior and reliable [26]. However, detection of CMV DNA by polymerase chain reaction (PCR), the gold standard for detection of CMV in body fluids, provides a better reflection of the presence of actively replicating virus. CMV PCR compared to immunoglobulin assays offers superior specificity $(100 \%$ vs $96 \%)$ and sensitivity $(100 \%$ vs $22 \%$ ) [42]. However, PCR may result in false positives for active CMV infection as it can also detect genetic material from latent viruses [43]. PCR is a relatively expensive assay that requires use of commercial kits and specialist equipment; hence, access to the technique in the African setting is limited. Thus, serology remains the method of choice. As such, seroprevalence is the main tool for CMV surveillance on the continent, hence forms the main focus of this review.

Exposure to CMV among African pregnant women in the reviewed studies was very high, but appears to vary across the continent. The prevalence of active infection, denoted by presence of IgM antibodies (0$15.5 \%$ ), was much lower than that of IgG antibodies $(60-100 \%)$ [29-39]. However, the seroprevalence of both CMV IgG and IgM antibodies did not show any geographic trends across the African continent. This observation probably rules out a possible role for geographical hotspots in CMV acquisition. The discrepancy between high CMV IgG seropositivity and low CMV IgM seropositivity suggests that the majority of the congenital CMV cases in high CMV prevalence settings in the reviewed studies are consequent of nonprimary infection [44]. Thus, CMV antibody avidity, an additional measurement meant to detect IgG positive individuals in whom CMV is likely to have been or is reactivated is critical in clinical decision making when serology is the only available method of diagnosis.

Two studies conducted in Egypt and Kenya reported avidity results and noticeably there were discrepancies between IgM seropositivity and low IgG avidity in both studies $[30,36]$. In the Egyptian study, $40 \%$ tested positive for IgM antibodies, but none of the participants that tested positive for CMV IgM antibodies had $\mathrm{IgG}$ antibodies of low avidity. This could suggest that CMV IgM antibodies persist in the circulation for longer than 6 weeks and hence may not be a good marker of current CMV infection [30]. On the other hand, the Kenyan study reported a low avidity IgG antibodies prevalence of $5 \%$, which was less than the $8 \%$ seroprevalence of $\operatorname{IgM}$ antibodies [36]. Such discrepancies between IgM and IgG avidity test outcomes highlight some of the challenges faced in detection of potentially vertically transmissible CMV infections during pregnancy. Despite IgG avidity being the readily available method for ascertaining recent/current infection in Africa, a previous study in Italian women found vertical transmission of CMV to be $4 \%$ and $2 \%$ among women with intermediate and high anti-CMV IgG antibody avidity, respectively [45]. Findings from the Italian study point out to potential misdiagnosis of women who are likely to transmit CMV to their offspring using serological tests. Therefore, determination of CMV DNA in blood (DNAemia) and that shed into other body fluids (viral shedding) presents a much more relevant and reliable test for active infection and potential vertical transmission in pregnant women.

In addition to CMV serology, one study reported CMV DNAemia as well as CMV shedding in various specimen types in pregnant women in the Gambia [31]. While CMV seropositivity was $100 \%$ in the Gambian population, CMV DNA prevalence was much lower in the different sample types tested: $29 \%$ in colostrum, $14 \%$ in vaginal swabs, $13 \%$ in saliva, $2 \%$ in plasma and $1 \%$ in urine [31]. It would have been interesting to compare the CMV DNA prevalence results with CMV avidity results to determine the concordance of the results. None of the studies included in this review provided such information. The $29 \%$ percent CMV DNA detection in colostrum suggests a huge 
contribution of breastfeeding to early vertical transmission of CMV [31].

Studies from Kenya, Sudan and one of the two from Nigeria report the lowest CMV seroprevalence frequencies $(<80 \%)$ [34,36-37], while the rest of the studies reviewed reported frequencies greater than $90 \%$ [29-33,35,38-39]. The differences in the prevalence rate across the African populations could be due to differences in other suggested or reported risk factors for CMV infection as well as study designs.

Factors associated with acquisition of CMV in African pregnant women

$\underline{\text { HIV co-infection }}$

Despite the reported association between CMV and HIV pathogenesis, there is a research gap on studies comparing prevalence of CMV between HIV-infected and HIV-uninfected pregnant women in African populations. For example, the $100 \%$ CMV IgG seroprevalence reported in the only two studies included in this review that considered $\mathrm{CMV} / \mathrm{HIV}$ coinfection may not be representative of the general Malawian and Gambian populations, but rather influenced by the HIV co-infection $[31,39]$.

$\mathrm{CMV}$, like other herpesviruses, may lie latent after initial infection if viral replication is significantly suppressed by T-lymphocytes [46]. CMV is reactivated later when the immune system fails to mount an adequate cell-mediated immune response to contain CMV replication, resulting in viral shedding. Consequently, the immune-compromised HIV-infected individuals are at a greater risk of CMV reactivation compared to HIV-uninfected individuals [47]. As a result, the risk of CMV reactivation is even higher in HIV-infected pregnant women whose already HIV compromised immunity is further down-regulated in pregnancy [3]. Some studies have observed that virtually all HIV-infected women are CMV IgG positive. Furthermore, CMV-specific IgG avidity results from these studies suggest reactivation of subclinical infection [48-49. The dynamics of HIV and CMV coinfection are not fully understood but the two have been found to co-activate each other in vitro [50]. Both CMV and HIV preferentially replicate in an activated environment, and there was a linear relationship between CMV and HIV viral load in the Kenyan infant study [51]. The relatively high prevalence of CMV in Africa could in part be driven by the HIV burden in the region [52]. Interestingly, one of the studies carried out among Nigerians showed a trend towards increased risk of being CMV IgG positive with having more than one sexual partner [34], a trend similar to what has been observed in risk of HIV infection [53]. Per contra, Barbosa et al. did not find any relationship between number of sexual partners and CMV viral shedding among Brazilian women [6].

$\mathrm{CMV}$ infection is an independent predictor of morbidity and mortality in HIV-infected individuals $[54,55]$. In a study carried out among HIV-infected infants in Kenya, CMV-induced increase in T-cell activation and apoptosis was hypothesised to contribute to rapid HIV disease progression in coinfected infants, suggesting a possible role of CMV in driving HIVassociated morbidity and mortality [56]. In another study carried out to determine the relationship between CMV DNAemia and maternal-infant mortality, HIV infected infants born to CMV DNAemic women had a four-fold increased risk of mortality within two years post-partum. The finding was independent of markers of HIV disease progression such as CD4+ T cell count and HIV viral load [57]. The discordance of CMV seroprevalence and HIV infection has also been shown in the Gambian population where a relatively high prevalence of cCMV (5.4\%) was reported among HIV unexposed infants [10]. It is worth noting that the Gambian study enrolled only healthy infants and excluded premature or low birth weight infants who would been at a higher risk of cCMV. The finding emphasises the potential burden of cCMV independent of and in addition to the high HIV burden in Africa.

In addition to HIV, inflammatory bowel disease (IBD) and colitis have been associated with a higher risk of CMV acquisition [58]. However, none of the studies reviewed here investigated or reported either IBD or colitis as a risk factor for CMV infection.

$\underline{\text { Socio-economic status }}$

Since CMV infection is transmitted through contact with infected body fluids, hygiene and hence socioeconomic status are important risk factors for CMV acquisition. The influence of education/literacy on CMV acquisition could be explained by the direct relationship between education and income which determines living conditions [59-60]. A study in Tanzania found urban residence to be a risk factor for CMV seropositivity when compared to rural residence [38]. The finding may be explained by the greater population densities in urban areas compared to rural areas, especially given that the study was conducted at a public medical facility, where there would be more human contact and an increased risk of CMV transmission. 


\section{Maternal age and parity}

The association of CMV seroprevalence and maternal age has been attributed to hygiene habits as well as contact with young children who may be at a higher risk of shedding CMV. A study by Pass et al. reported higher rates of CMV infection among parents of children who attended day care [61]. The children in day care are exposed to CMV through interaction with their peers, hence increase risk of CMV exposure. The Tanzanian study reviewed here reported a significant association between younger maternal age and increased risk of CMV seropositivity. They argued that the older mothers have more household experience and are more aware of their surroundings, hence develop better hygiene habits which reduce risk of $\mathrm{CMV}$ acquisition or transmission $[38,62]$. Findings from the Tanzanian study are supported by findings from an earlier study where younger maternal age was significantly associated with poor hygiene and increased risk of CMV infection [63-64].

Parity is defined as the number of term pregnancies a woman has had, regardless of whether they led to spontaneous abortion, stillbirth or livebirth. In the Kenyan [36] study reviewed, high parity was defined as having more than four children prior to the current pregnancy, while in the Sudanese [37] study, it was defined as having more than five children prior to the current pregnancy. Both the Kenyan and Sudanese studies reported a significant association between higher parity and risk of anti-CMV IgG seropositivity. Other studies have however reported conflicting findings, likewise, with the speculation that women with lower parity would be younger and less experienced, hence at a greater risk of CMV acquisition and transmission [63]. Thus, the role of parity in CMV acquisition remains contentious with need for further research, perhaps using CMV DNA and IgM seropositivity instead of the largely ubiquitous IgG seropositivity.

\section{$\underline{\text { Blood transfusion }}$}

CMV infection can be transmitted through transfusion of CMV-infected blood [65]. It is possible that some participants could have received CMVinfected transfused blood, perhaps due to lack of CMV screening in the blood products intended for transfusion. CMV acquired through blood transfusion could be reactivated in settings of compromised immunity and pregnancy, thus increasing the risk of vertical transmission. Presence of anti-CMV antibodies in transfused blood does not necessarily reflect the virological status of the donor, hence is not an accurate proxy for the risk of transmission. Thus, more definitive diagnostic tests such as CMV DNA PCR are critical in making a reliable conclusion on the safety of blood intended for transfusion. Unfortunately, in Africa, serology remains the method of choice for CMV screening in blood products [26]. Given the discrepancies in seroprevalence, avidity and CMV DNA status reported and discussed in earlier sections, pregnant women may still be receiving $\mathrm{CMV}$ contaminated blood through transfusion.

\section{$\underline{\text { Recurrent spontaneous abortion }}$}

Recurrent spontaneous abortion is defined as three or more consecutive pregnancy losses. Evidence has shown that potentially preventable infections may account for up to $66 \%$ of spontaneous abortions $[15,66]$. Infections such as Mycoplasma hominis, herpes simplex virus type 2 as well as CMV have been found to lead to inflammatory processes which result in spontaneous abortion [66-67]. In addition to CMV inducing inflammatory processes that increase apoptosis in trophoblast cells during pregnancy, CMV also activates TNF- $\alpha$, leading to cell death [15]. Furthermore, CMV has also been shown to disturb normal physiology of placental cells, resulting in placental dysfunction and increased risk of spontaneous abortion or still birth $[66,68]$. The non-significant associations of CMV with spontaneous abortion reported in the Sudanese study could be attributed to an overrepresentation ( $80 \%$ vs $20 \%$ ) of women without a history of recurrent spontaneous abortion in the study cohort, therefore minimising the effect of CMV on underrepresented women.

Other possible factors associated with CMV infection but not evaluated in African studies

Genetic predisposition

Polymorphisms in host genes encoding factors involved in innate immunity have been found to influence CMV acquisition [69]. Genes coding for TLR as well as NK cell surface receptors have been implicated.

TLRs are protein recognition receptors which sense the presence of pathogen associated molecular patterns to mediate and trigger an immune response, particularly nuclear factor-kappa B (NF- $\mathrm{B}$ ) activation and cytokine secretion [70]. TLR2, 4 and 9 are the major TLRs involved in immune responses against dsDNA viruses such as CMV [71]. On the TLR2 gene, carriage of the C allele on the $1350 \mathrm{~T}>\mathrm{C}$ polymorphic site and that of the A allele on the $2258 \mathrm{G}>\mathrm{A}$ polymorphic site were associated with increased susceptibility to cCMV 
infection among Japanese children [72]. Two polymorphisms on the TLR4 gene (896A $>\mathrm{G}$ and 1196 $\mathrm{C}>\mathrm{T}$ ) were significantly associated with the risk factors for invasive aspergillosis that included CMV seropositivity [73]. A study performed among Polish foetuses and neonates reported increased risk of infection with $1486 \mathrm{~T}>\mathrm{C}$ and $2848 \mathrm{G}>\mathrm{A}$ SNPs on the TLR9 gene [74]. Polymorphisms that are associated with increased susceptibility to CMV infection involve a nucleotide change which results in a less potent protein being produced [72]. In contrast, Jablonska et al. reported no association between polymorphism in the TLR2 (1350T $>\mathrm{C}, 2258 \mathrm{G}>\mathrm{A})$ and TLR4 $(896 \mathrm{~A}>\mathrm{G}$ and $1196 \mathrm{C}>\mathrm{T}$ ) genes and risk of cCMV infection among infants, but reported a decreased CMV infection risk in adults carrying the TLR2 2258A allele [75]. Polymorphisms in the TLR genes that confer protection against CMV infection encode potent and relatively highly functional TLR proteins.

NK cells expressing the human leukocyte antigen (HLA) E-binding receptor NKG2C have been found to be particularly important for CMV control [76-77]. A deletion in $N K G 2 C$, a gene that encodes for the NKG2C receptor protein has been associated with decreased absolute number of $\mathrm{NKG}_{2} \mathrm{C}^{+} \mathrm{NK}$ cells, with a decreased expression of $\mathrm{NKG} 2 \mathrm{C}$ receptors on the NK cell surface as well as lower activation and degranulation of $\mathrm{NKG}_{2} \mathrm{C}^{+} \mathrm{NK}$ cells. Studies have found transplant patients who are heterozygous or homozygous for the deletion to be at an increased risk of CMV reactivation and symptomatic CMV disease after immunosuppressive therapy [78]. It is important to note that the allele and genotype frequencies of the $N K G 2 C$ deletion differ across populations [79] and so findings may not be generalised. Genetic findings should therefore be population-specific especially considering the genetic differences between Africans and other world populations, and the extensive genetic diversity within Africa. Of note is the high prevalence of the $N K G 2 C$ deletion among African population compared with other populations. The NKG2C genotype frequencies further demonstrate a striking difference between East and West Africans [79].

Variation in genes encoding human leukocyte antigen (HLA) and killer cell immunoglobulin like $(K I R)$ receptors have also been widely implicated in susceptibility or resistance to infection and disease progression of various viruses due to their critical role in immune regulation [80]. Considering that CMV has an extensive repertoire of mechanisms for immune evasion, polymorphisms in genes encoding proteins involved in the immune cascade such as IL, IFN and
$\mathrm{TNF} \alpha$ may play a role CMV infection [81]. However, relatively little is known about genetic predisposition to CMV infection and transmission, particularly in the African setting, yet knowledge of such genetic determinants may yield novel therapeutic targets for CMV.

\section{Gut microbiome profiles}

Gut microbiome profiles shape the microbial and immunological environment of the gut, hence indirectly protect against pathogenic infections and influence immune responses [82-83]. An altered microbiome has been associated with an increased risk of disease acquisition, with some bacterial species being protective against infection while others have a more pro-inflammatory effect. Gut microbiome dysbiosis in pregnancy may weaken immunity, thereby facilitating antenatal infections such as CMV which place the developing foetus at risk [84-85]. In addition to the possible pregnancy induced microbiome dysbiosis, CMV replication in the gut epithelia has been associated with disruption of the tight junctions of the gut epithelia which results in increased intestinal permeability [86]. This effect of CMV on the intestinal epithelia has been found to be partly mediated by the CMV-induced proinflammatory cytokine IL-6. The effect of CMV on the integrity of the gut epithelia has been described in HIV-coinfected individuals [87], leading to disruption of the gut barrier and microbial translocation, which in turn fuel immune activation and inflammation and result in poorer outcomes [83]. CMV, independent of HIV, results in the tight junction disruption as treatment with letermovir, an anti-CMV drug, dampens the effects of CMV on the gut by restoring the epithelia [87]. As such, CMV infection may be associated with certain aberrations in gut microbiome profiles [88]. A recent longitudinal study found that gut colonisation by Staphylococcus aureus was protective against early acquisition of CMV infection [89]. Barton et al. reported that latent CMV infection confers protection against symbiotic bacterial infection [90], further emphasizing the possible role of CMV on the normal gut flora. However, none of the studies reviewed here investigated possible relationships between CMV infection and gut microbiome profiles, so this represents an important area for future research.

Immune activation

Immune activation is characterised by chronic inflammation and stimulation of immune cells, which in turn secrete inflammatory factors such as cytokines 
and chemokines in response to infection or immune dysregulation [91]. In addition, there is sustained immune cell proliferation which exhausts naïve immune cells. This immune environment facilitates inflammation and viral replication in host cells, hence increasing chances of viral shedding into the mucosa and body fluids. CMV has been described as a disease of inflammation in pregnancy [92], but the dynamics of immune activation, CMV DNAemia and CMV acquisition/transmission are unknown. In the study carried out among Kenyan HIV-infected infants, mentioned earlier in this review, the CMV-induced increase in T-cell activation and apoptosis observed could potentially be a marker of CMV-induced immune activation [51]. Also, since CMV has been found to have a synergistic intracellular co-activation with HIV, it is possible that $\mathrm{CMV}$ is also sustained by chronic immune activation [47]. The ability of CMV to evade host innate immunity may also implicate CMV infection in chronic immune activation. Interestingly, chronic immune activation is associated with gut microbiome dysbiosis [85]. However, not much work has been done into investigating the role of chronic immune activation in sustaining CMV infection.

\section{Conclusion}

The risks of CMV infection and reactivation are determined by a variety of host, viral and environmental factors. However there still is a knowledge gap on the extent to which these various factors are operating in Africa, especially compared with the developed world, yet Africa is one of the regions with the greatest CMV burden. In the absence of a vaccine, it would be worthwhile to develop more rigorous and sensitive diagnostic tools, especially targeting women in the reproductive-age group, who have the greatest potential risks for CMV acquisition and reactivation with the consequent risk of vertical transmission. The initiation of CMV education to women by the American Medical Society resulted in a drastic decrease in CMV prevalence [93]. It might therefore also be valuable to educate African women on the possible effects of maternal and congenital CMV infection and the necessary steps to avoid acquisition and transmission to the fetus and neonate, wherever and whenever possible.

Most of the studies investigating the role of HIV in CMV infection were carried out prior to the roll-out of the universal Option B+ (lifelong ART regardless of CD4+ Tcell count) by the WHO. The role of ART in CMV reactivation and risk of cCMV in HIV exposed children remains unclear. Studies on the potential role of ART in reducing risk of cCMV among HIV exposed infants are especially needed in Africa where there is a high burden of HIV. High birth rates of HIV exposed children who have been described to be more prone to disease and disability compared to their HIV-uninfected counterparts also necessitates these studies. This is further emphasized by several studies which have reported cCMV rates of between three and $11 \%$ in HIV exposed infants, potentially contributing to hearing loss and other disabilities in HIV-exposed children. As reviewed by Manickal et al. [1], in South Africa alone, over 18,000 infants are estimated to be born with cCMV infection each year [1]. In addition to the HIV burden, a study by Slyker et al. reported a discrepancy in the rate of CMV DNA detection in plasma, cervical secretions and breast milk samples [94]. This points to the possibility of missing potentially transmitting mothers using only the widely-used plasma samples. Hence, there is need for more studies exploring methods of detecting CMV in different body compartments in the pregnant women and determining their predictive value for vertical transmission, so as to curb the burden of cCMV and its disabling effects for African children.

\section{Acknowledgements}

We would like to acknowledge all the authors for their various and equal contributions in coming up with this review. Dandara's group is funded by the National Research Foundation (NRF) and the South Africa Medical Research Council (SAMRC).

\section{References}

1. Manicklal S, Emery VC, Lazzarotto T, Boppana SB, Gupta RK (2013) The "silent" global burden of congenital cytomegalovirus. Clin Microbiol Revs 26: 86-102.

2. Ross SA, Ahmed A, Palmer AL, Michaels MG, Sánchez PJ, Bernstein DI, Tolan RW, Jr Novak Z, Chowdhury N, Fowler KB, Boppana SB (2014) Detection of congenital cytomegalovirus infection by real-time polymerase chain reaction analysis of saliva or urine specimens. J Infect Dis 210:1415-1418.

3. Mor G, Cardenas I (2010) The immune system in pregnancy: A unique complexity. Am J Reprod Immunol 63: 425-433.

4. Boppana SB, Rivera LB, Fowler KB, Mach M, Britt WJ (2001) Intrauterine transmission of cytomegalovirus to infants of women with preconceptional immunity. N Engl J Med 344: 1366-1371.

5. Revello MG, Lazzarotto T, Guerra B, Spinillo A, Ferrazzi E, Kustermann A, Guaschino S, Vergani P, Todros T, Frusca T (2014) A randomized trial of hyperimmune globulin to prevent congenital cytomegalovirus. N Engl J Med 370: 1316-1326.

6. Barbosa NG, Yamamoto AY, Duarte G, Aragon DC, Fowler KB, Boppana S, Britt WJ, Mussi-Pinhata MM (2018) Cytomegalovirus shedding in seropositive pregnant women from a high-seroprevalence population: the Brazilian cytomegalovirus hearing and maternal secondary infection study. Clin Infect Dis 67: 743-750. 
7. Dar L, Pati SK, Patro ARK, Deorari AK, Rai S, Kant S, Broor S, Fowler KB, Britt WJ, Boppana SB (2008) Congenital cytomegalovirus infection in a highly seropositive semi-urban population in India. Pediatr Infect Dis J 27: 841-843.

8. Mussi-Pinhata MM, Yamamoto AY, Moura Brito RM, de Lima Isaac M, de Carvalho e Oliveira PF, Boppana S, Britt WJ (2009) Birth prevalence and natural history of congenital cytomegalovirus infection in a highly seroimmune population. Clin Infect Dis 49: 522-528.

9. Townsend CL, Forsgren M, Ahlfors K, Ivarsson S-A, Tookey PA, Peckham CS (2013) Long-term outcomes of congenital cytomegalovirus infection in Sweden and the United Kingdom. Clin Infect Dis 56:1232-1239.

10. van der Sande MAB, Kaye S, Miles DJC, Waight P, Jeffries DJ, Ojuola OO, Palmero M, Pinder M, Ismaili J, Flanagan KL, Aveika AA, Zaman A, Rowland-Jones S, McConkey SJ, Hilton C. Whittle HC, Marchant A (2007) Risk factors for and clinical Outcome of congenital cytomegalovirus infection in a peri-urban West-African birth cohort. PLoS One 2: e492.

11. Wang C, Zhang X, Bialek S, Cannon MJ (2011) Attribution of congenital cytomegalovirus infection to primary versus nonprimary maternal infection. Clin Infect Dis 52: 11-13.

12. Ornoy A, Diav-Citrin O (2006) Fetal effects of primary and secondary cytomegalovirus infection in pregnancy. Reproductive Toxicol 21: 399-409.

13. Mussi-Pinhata MM, Yamamoto AY, Aragon DC, Duarte G, Fowler KB, Boppana S, Britt WJ (2018) Seroconversion for cytomegalovirus infection during pregnancy and fetal infection in a highly seropositive population: "The BraCHS Study." J Infect Dis 218: 1200-1204.

14. Yamamoto AY, Castellucci RC, Aragon DC, Mussi-Pinhata MM (2013) Early high CMV seroprevalence in pregnant women from a population with a high rate of congenital infection. Epidemiol Infect 141: 2187-2191.

15. Giakoumelou S, Wheelhouse N, Cuschieri K, Entrican G, Howie SEM, Horne AW (2016) The role of infection in miscarriage. Hum Reprod Update 22: 116-133.

16. Dollard SC, Grosse SD, Ross DS (2007) New estimates of the prevalence of neurological and sensory sequelae and mortality associated with congenital cytomegalovirus infection. Rev Med Virol 17: 355-363.

17. Kimberlin DW, Jester PM, Sánchez PJ, Ahmed A, Arav-Boger R, Michaels MG, Ashouri N (2015) Valganciclovir for symptomatic congenital cytomegalovirus disease. N Engl J Med 372: 933-943.

18. Mahadevia PJ, Gebo KA, Pettit K, Dunn JP, Covington MT (2004) The epidemiology, treatment patterns, and costs of cytomegalovirus retinitis in the post-haart era among a national managed-care population. J Acquir Immune Defic Syndr 36: 972-977.

19. Tagar E, Sundaram M, Condliffe K, Matatiyo B, Chimbwandira F, Chilima B, Mwanamanga R, Moyo C, Chitah BM, Nyemazi JP, Assefa Y, Pillay Y, Mayer S, Shear L, Dain M, Hurley R, Kumar R, McCarthy T, Batra P, Gwinnell D, Diamond S, Over M(2014) Multi-country analysis of treatment costs for HIV/AIDS (MATCH): facility-level ART unit cost analysis in Ethiopia, Malawi, Rwanda, South Africa and Zambia. PLos One 9: e108304.

20. Chen S, Ravallion M (2010) The developing world is poorer than we thought, but no less successful in the fight against poverty. Q J Econ 125: 1577-1625.

21. Roxby AC, Atkinson C, Ásbjörnsdóttir K, Farquhar C, Kiarie JN, Drake AL, Wald A, Boeckh M, Richardson B, Emery V (2014). Maternal valacyclovir and infant cytomegalovirus acquisition: a randomized controlled trial among HIV-infected women. PLoS One 9: e87855.
22. Plachter B (2016) Prospects of a vaccine for the prevention of congenital cytomegalovirus disease. Med Microbiol Immunol 205: 537-547.

23. Lanzieri TM, Dollard SC, Bialek SR, Grosse SD (2014) Systematic review of the birth prevalence of congenital cytomegalovirus infection in developing countries. Int J Infect Dis 22: 44-48.

24. Adland E, Klenerman P, Goulder P, Matthews PC (2015) Ongoing burden of disease and mortality from HIV/CMV coinfection in Africa in the antiretroviral therapy era. Front Microbiol: 6: 1016.

25. United Nations Programme on HIV/AIDS (UNAIDS) (2017) 90-90-90 An ambitious treatment target to help end the AIDS epidemic. Available: https://www.unaids.org/en/resources/documents/909090. Accessed: 5 June 2019

26. Ross SA, Novak Z, Pati S, B Boppana S (2011) Overview of the diagnosis of cytomegalovirus infection. Infect Disord Drug Targets 11: 466-474.

27. Chan KH, Sonnenberg K, Niedrig M, Lam SY, Pang CM, Chan KM, Ma SK, Seto WH, Peiris JS (2007) Use of antibody avidity assays for diagnosis of severe acute respiratory syndrome coronavirus infection. Clin Vaccine Immunol 14: 1433-1436.

28. Villard O, Breit L, Cimon B, Franck J, Fricker-Hidalgo H, Godineau N, Houze S, Paris L, Pelloux H, Villena I, Candolfi E; French National Reference Center for Toxoplasmosis Network (2013) Comparison of four commercially available avidity tests for toxoplasma gondii-specific IgG antibodies. Clin Vaccine Immunol 20: 197-204.

29. el-Sayed Zaki M, Goda H (2007) Relevance of parvovirus B19, herpes simplex virus 2 , and cytomegalovirus virologic markers in maternal serum for diagnosis of unexplained recurrent abortions. Arch Pathol Lab Med 131: 956-960.

30. Kamel N, Metwally L, Gomaa N, Sayed Ahmed WA, Lotfi M, Younis S (2014) Primary cytomegalovirus infection in pregnant Egyptian women confirmed by cytomegalovirus IgG avidity testing. Med Princ Pract 23: 29-33.

31. Kaye S, Miles D, Antoine P, Burny W, Ojuola B, Kaye P, Rowland-Jones S, Whittle H, Sande M, Marchant A (2008) Virological and immunological correlates of mother-to-child transmission of cytomegalovirus in The Gambia. J Infect Dis 197: 1307-1314.

32. Völker F, Cooper P, Bader O, Uy A, Zimmermann O, Lugert R, Groß, U (2017) Prevalence of pregnancy-relevant infections in a rural setting of Ghana. BMC Pregnancy Childbirth 17: 172.

33. Akende O, Akanbi OA, Oluremi AS, Okonko IO, Opaleye OO (2016) Prevalence of cytomegalovirus IgG antibodies among pregnant women visiting antenatal clinic, LAUTECH Teaching Hospital in Osogbo, Osun State, Nigeria. J Immunoassay Immunochem 37: 289-295.

34. Hamid KM, Onoja AB, Tofa UA, Garba KN (2014) Seroprevalence of cytomegalovirus among pregnant women attending Murtala Mohammed Specialist Hospital Kano, Nigeria. Afr Health Sci 14: 125-130.

35. Yeshwondm M, Balkachew N, Delayehu B, Mekonen G. Seroepidemiology (2016) Study of cytomegalovirus and rubella among pregnant women at St. Paul's Hospital Millennium Medical College, Addis Ababa, Ethiopia. Ethiop J Health Sci 26: 427-438.

36. Maingi Z, Nyamache AK (2014) Seroprevalence of Cytomegalo Virus (CMV) among pregnant women in Thika, Kenya. BMC Res Notes 7: 794.

37. Hamdan HZ, Abdelbagi IE, Nasser NM, Adam I (2011) Seroprevalence of cytomegalovirus and rubella among pregnant women in western Sudan. Virol J 8: 217. 
38. Chibwe E, Mirambo MM, Kihunrwa A, Mshana SE (2017) Magnitude of the Cytomegalovirus infection among pregnant women attending antenatal clinics in the city of Mwanza, Tanzania. BMC Res Notes 10: 489.

39. Giuliano M, Pirillo MF, Liotta G, Andreotti M, Jere H, Sagno JB, Ciccacci F, Amici R, Marazzi MC, Vella S (2017) High CMV IgG antibody levels are associated to a lower CD4+ response to antiretroviral therapy in HIV-infected women. J Clin Virol 96: 17-19.

40. Lawrence GM, Friedlander Y, Calderon-Margalit R, Enquobahrie DA, Huang JY, Tracy RP, Manor O, Siscovick DS, Hochner H (2017) Associations of social environment, socioeconomic position and social mobility with immune response in young adults: the Jerusalem Perinatal Family Follow-Up Study. BMJ Open 7: e016949.

41. Cannon MJ, Davis, KF (2005) Washing our hands of the congenital cytomegalovirus disease epidemic. BMC Public Health 5: 70.

42. Nelson CT, Istas AS, Wilkerson MK, Demmler GJ (1995) PCR detection of cytomegalovirus DNA in serum as a diagnostic test for congenital cytomegalovirus infection. J Clin Microbiol 33: 3317-3318.

43. Abedi E, Kheirandish M, Sharifi Z, Samiee S, Kokhaei P, Pourpak Z, Ashraf MJ (2017) Quantification of active and latent form of human cytomegalovirus infection in umbilical cord blood donors by real-time PCR. Int J Organ Transplant Med 8: 140-145.

44. Kenneson A, Cannon MJ (2007) Review and meta-analysis of the epidemiology of congenital cytomegalovirus (CMV) infection. Rev Med Virol 17: 253-276.

45. Lazzarotto T, Gabrielli L, Lanari M, Guerra B, Bellucci T, Sassi M, Landini MP (2004) Congenital cytomegalovirus infection: recent advances in the diagnosis of maternal infection. Hum Immunol 65: 410-415.

46. Huang L, Langerak AW, Baan CC, Litjens NHR, Betjes MGH (2016) Latency for cytomegalovirus impacts $\mathrm{T}$ cell ageing significantly in elderly end-stage renal disease patients. Clin Exp Immunol 186: 239-248.

47. Christensen-Quick A, Vanpouille C, Lisco A, Gianella S (2017) Cytomegalovirus and HIV persistence: pouring gas on the fire. AIDS Res Hum Retroviruses 33 Suppl 1: 23-30.

48. Itell HL, Nelson CS, Martinez DR, Permar SR (2017) Maternal immune correlates of protection against placental transmission of cytomegalovirus. Placenta 60 Suppl 1: 73-79.

49. Reitter A, Buxmann H, Haberl A, Schlösser R, Kreibich M, Keppler O, Berger A (2016) Incidence of CMV co-infection in HIV-positive women and their neonates in a tertiary referral centre: a cohort study. Med Microbiol Immunol 205: 63-71.

50. Freeman ML, Lederman MM, Gianella S (2016). Partners in crime: the role of CMV in immune dysregulation and clinical outcome during HIV infection. Curr HIV/AIDS Rep 13: 1019.

51. Slyker JA, Lohman-Payne BL, John-Stewart GC, MalecheObimboc E, Emery S, Richardson B, Dong T, K.N. Iversen AKN, Mbori-Ngacha D, Overbaugh J, Emery VC, RowlandJones S (2009) Acute cytomegalovirus infection in Kenyan HIV-infected infants. AIDS 23: 2173-2181.

52. UNAIDS (2018) Global HIV \& AIDS statistics. Fact sheet Available: http://www.unaids.org/en/resources/fact-sheet. Accessed: 05 January 2019

53. Do M, Meekers D (2009). Multiple sex partners and perceived risk of HIV infection in Zambia: attitudinal determinants and gender differences. AIDS Care 21: 1211-1221.

54. Francisci D, Tosti A, Baldelli F, Stagni G, Pauluzzi S (1997) The pp65 antigenaemia test as a predictor of cytomegalovirus- induced end-organ disease in patients with AIDS. AIDS 11: $1341-1345$.

55. Salzberger B, Hartmann P, Hanses F, Uyanik B, Cornely O, Wöhrmann A, Fätkenheuer G (2005) Incidence and prognosis of CMV disease in HIV-infected patients before and after introduction of combination antiretroviral therapy. Infection 33: 345-349.

56. Slyker JA, Rowland-Jones SL, Dong T, Reilly M, Richardson B, Emery VC, Atzberger A, Mbori-Ngacha D, Lohman-Payne BL, John-Stewart GC (2012) Acute cytomegalovirus infection is associated with increased frequencies of activated and apoptosis-vulnerable T cells in HIV-1-infected infants. J Virol 86: 11373-11379.

57. Slyker JA, Lohman-Payne BL, Rowland-Jones SL, Otieno P, Maleche-Obimbo E, Richardson B, Farquhar C, Mbori-Ngacha D, Emery VC, John-Stewart GC (2009) The detection of cytomegalovirus DNA in maternal plasma is associated with mortality in HIV-1 infected women and their infants. AIDS 23: $117-124$

58. Liu C-C, Ji S, Ding Y, Zhou L, Liu X, Li W (2018) Cytomegalovirus infection and steroid-refractory inflammatory bowel disease: possible relationship from an updated meta-analysis. Ir J Med Sci 187: 935-942.

59. Hoes J, Boef AGC, Knol MJ, de Melker HE, Mollema L, van der Klis FRM, Rots NY, van Baarle D (2018) Socioeconomic status is associated with antibody levels against vaccine preventable diseases in the Netherlands. Front Public Health 6: 209.

60. Meier HCS, Haan MN, Mendes de Leon CF, Simanek AM, Dowd JB, Aiello AE (2016) Early life socioeconomic position and immune response to persistent infections among elderly Latinos. Soc Sci Med 166: 77-85.

61. Pass RF, Hutto C, Ricks R, Cloud GA (1986) Increased rate of cytomegalovirus infection among parents of children attending day-care centers. N Engl J Med 314: 1414-1418.

62. Jin Q, Su J, Wu S (2017) Cytomegalovirus Infection among pregnant women in Beijing: sero-epidemiological survey and intrauterine transmissions. J Microbiol Biotechnol 27: 10051009.

63. Fowler KB, Stagno S, Pass RF (1993) Maternal age and congenital cytomegalovirus infection: screening of two diverse newborn populations, 1980-1990. J Infect Dis 168: 552-556.

64. Sherriff A, Golding J, Team TAS (2002) Factors associated with different hygiene practices in the homes of 15 month old infants. Arch Dis Child 87: 30-35.

65. Ziemann M, Thiele T (2017) Transfusion-transmitted CMV infection - current knowledge and future perspectives. Transfus Med 27: 238-248.

66. Oliveira GM, Pascoal-Xavier MA, Moreira DR, Guimarães VS, Aguiar RA, Miranda D, Romanelli R (2017) Detection of cytomegalovirus, herpes virus simplex, and parvovirus b19 in spontaneous abortion placentas. J Matern Fetal Neonatal Med 32: $1-8$.

67. Cao C-J, Wang Y-F, Fang D-M, Hu Y (2018) Relation between mycoplasma infection and recurrent spontaneous abortion. Eur Rev Med Pharmacol Sci 22: 2207-2211.

68. Sinzger C, Jahn G (1996) Human cytomegalovirus cell tropism and pathogenesis. Intervirology 39: 302-319.

69. Gelemanović A, Dobberpuhl K, Krakar G, Patarčić I, Kolčić I, Polašek O (2016) Host genetics and susceptibility to congenital and childhood cytomegalovirus infection: a systematic review. Croat Med J 57: 321-330.

70. Boehme KW, Guerrero M, Compton T (2006) Human cytomegalovirus envelope glycoproteins $\mathrm{B}$ and $\mathrm{H}$ are necessary for TLR2 activation in permissive cells. J Immunol 177: 70947102 . 
71. Wujcicka W, Wilczyński J, Nowakowska D (2014) Alterations in TLRs as new molecular markers of congenital infections with Human cytomegalovirus? Pathog Dis 70: 3-16.

72. Taniguchi R, Koyano S, Suzutani T, Goishi K, Ito Y, Morioka I, Oka A, Nakamura H, Yamada H, Igarashi T, Inoue N (2013) Polymorphisms in TLR-2 are associated with congenital cytomegalovirus (CMV) infection but not with congenital CMV disease. Int J Infect Dis 17: 1092-1097.

73. Bochud P-Y, Chien JW, Marr KA, Leisenring WM, Upton A, Janer M, Rodrigues SD, Li S, Hansen JA, Zhao LP, Aderem A, Boeckh M (2008) Toll-like receptor 4 polymorphisms and aspergillosis in stem-cell transplantation. N Engl J Med 359: 1766-1777.

74. Paradowska E, Jabłońska A, Studzińska M, Skowrońska K, Suski P, Wiśniewska-Ligier M, Woźniakowska-Gęsicka T, Nowakowska D, Gaj Z, Wilczyński J, Leśnikowski1 Z (2016) TLR9 $-1486 \mathrm{~T} / \mathrm{C}$ and $2848 \mathrm{C} / \mathrm{T}$ SNPs Are associated with human Cytomegalovirus infection in infants. PLos One 11: e0154100.

75. Jabłońska A, Paradowska E, Studzińska M, Suski P, Nowakowska D, Wiśniewska-Ligier M, WoźniakowskaGęsicka T, Wilczyński J, Leśnikowski ZJ (2014) Relationship between Toll-like receptor 2 Arg677Trp and Arg753Gln and Toll-like receptor 4 Asp299Gly polymorphisms and cytomegalovirus infection. Int J Infect Dis 25: 11-15.

76. Muntasell A, López-Montañés M, Vera A, Heredia G, Romo N, Peñafiel J, Moraru M, Vila J, Vilches C, López-Botet M (2013) NKG2C zygosity influences CD94/NKG2C receptor function and the NK-cell compartment redistribution in response to human cytomegalovirus. Eur J Immunol 43: 32683278.

77. López-Botet M, Vilches C, Redondo-Pachón D, Muntasell A, Pupuleku A, Yélamos J, Pascual J, M (2017) Dual Role of Natural Killer Cells on Graft Rejection and Control of Cytomegalovirus Infection in Renal Transplantation. Front Immunol 16: 8.

78. Vietzen H, Pollak K, Honsig C, Jaksch P, Puchhammer-Stöckl E (2018) NKG2C deletion is a risk factor for human cytomegalovirus viremia and disease after lung transplantation. J Infect Dis 217: 802-806.

79. Goncalves A, Makalo P, Joof H, Burr S, Ramadhani A, Massae P, Malisa A (2016) Differential frequency of NKG2C/KLRC2 deletion in distinct African populations and susceptibility to Trachoma: a new method for imputation of KLRC2 genotypes from SNP genotyping data. Hum Genet 135: 939-951.

80. Błachowicz O, Zwolińska K (2016) The role genes encoding of killer cell immunoglobulin-like receptors (KIRs) and their ligands in susceptibility to and progression of HIV infection. Postepy Hig Med Dosw 70: 1409-1423.

81. Wujcicka W, Paradowska E, Studzińska M, Wilczyński J, Nowakowska D (2017). Toll-like receptors genes polymorphisms and the occurrence of HCMV infection among pregnant women. Virol J 14: 64.

82. Bohnhoff M, Drake BL, Miller CP (1954). Effect of Streptomycin on Susceptibility of Intestinal Tract to Experimental Salmonella Infection. Proc Soc Exp Biol Med 86: $132-137$.

83. Leeansyah E, Malone DFG, Anthony DD, Sandberg JK (2013). Soluble biomarkers of HIV transmission, disease progression and comorbidities. Curr Opin HIV AIDS 8: 117-124.

84. Fox C, Eichelberger K (2015). Maternal microbiome and pregnancy outcomes. Fertil Steril 104: 1358-1363.
85. Tanaka K, Sawamura S, Satoh T, Kobayashi K, Noda S (2007). Role of the indigenous microbiota in maintaining the virusspecific CD8 memory T cells in the lung of mice infected with murine cytomegalovirus. J Immunol 178: 5209-5216.

86. de Maar EF, Kleibeuker JH, Boersma-van Ek W, The TH, van Son WJ (1996). Increased intestinal permeability during cytomegalovirus infection in renal transplant recipients. Transpl Int 9: 576-580.

87. Maidji E, Somsouk M, Rivera JM, Hunt PW, Stoddart CA (2017). Replication of CMV in the gut of HIV-infected individuals and epithelial barrier dysfunction. PLoS Pathog 13: e1006202

88. Gianella S, Chaillon A, Mutlu EA, Engen PA, Voigt RM, Keshavarzian A, Losurdo J, Chakradeo P, Lada SM, Nakazawa M, Landay AL (2017) Effect of CMV and EBV replication on intestinal mucosal gene expression and microbiome composition of HIV-infected and uninfected individuals. AIDS 31: 2059-2067.

89. Carvalho-Queiroz C, Johansson MA, Persson JO, Jörtsö E, Kjerstadius T, Nilsson C, Saghafian-Hedengren S, Sverremark-Ekström E (2016) Associations between EBV and CMV seropositivity, early exposures, and gut microbiota in a prospective birth cohort: a 10-Year Follow-up. Front Pediatr 4: 93.

90. Barton ES, White DW, Cathelyn JS, Brett-McClellan KA, Engle M, Diamond MS, Miller VL, Virgin, HW (2007) Herpesvirus latency confers symbiotic protection from bacterial infection. Nat 447: 326-329.

91. Paiardini M, Müller-Trutwin M (2013) HIV-associated chronic immune activation. Immunol Revs 254: 78-101.

92. Yeo KT, Embury P, Anderson T, Mungai P, Malhotra I, King C, Kazura J, Dent A (2019) HIV, cytomegalovirus, and malaria infections during pregnancy lead to inflammation and shifts in memory B cell subsets in Kenyan neonates. J Immunol 202: $1465-1478$

93. Chauhan SP, Berghella V, Sanderson M, Magann EF, Morrison JC (2006) American college of obstetricians and gynecologists practice bulletins: an overview. Ame J Obstet Gynecol 194: 1072-1075.

94. Slyker J, Farquhar C, Atkinson C, Ásbjörnsdóttir K, Roxby A, Drake A, Kiarie J, Wald A, Boeckh M, Richardson B, OdemDavis K, John-Stewart G, Emery V (2014) Compartmentalized cytomegalovirus replication and transmission in the setting of maternal HIV-1 infection. Clin Infect Dis 58: 564-572.

\section{Corresponding author}

Professor Collet Dandara, $\mathrm{PhD}$

Pharmacogenomics and Drug Metabolism Group

Division of Human Genetics,

Department of Pathology \& Institute of Infectious Disease and

Molecular Medicine

University of Cape Town

Faculty of Health Sciences

7925 Anzio Road, Observatory

Cape Town, South Africa

Phone: +27214066506

Fax: +27 216502010

Email: collet.dandara@uct.ac.za

Conflict of interests: No conflict of interests is declared. 